\section{Stimulus information vs processing time in auditory pattern recognition*}

\author{
DOMINIC W. MASSARO+ \\ University of Wisconsin, Madison, Wisconsin 53706
}

\begin{abstract}
Previous studies have shown that pitch perception improves with increases in tone duration. An increase in tone duration increases the information available in the stimulus presentation. Other recent experiments have shown that sufficient perceptual processing time is also necessary for accurate pitch perception. The present study determines the relative contribution of stimulus information and processing time in an absolute pitch indentification task. The results indicate that processing time is more critical than stimulus information. The results are described accurately by a model that describes the perceptual process in terms of the information in the stimulus and the time the information is available for perceptual processing.
\end{abstract}

An auditory perception of pitch quality of tonal stimuli requires some minimal stimulus duration (Creel, Boomsliter, \& Powers, 1970; Doughty \& Garner, 1947; Stevens \& Davis, 1938 ). Tones lasting a few milliseconds are heard as clicks, while, with longer durations, they take on a tonal quality. The improvement of pitch perception with tone duration is also supported by the observation that the accuracy of pitch discrimination improves with increases in the duration of tonal stimuli (Anderson, 1914; Békésy, 1960; Turnbull, 1944). For example, Békésy found that the just noticeable frequency difference for an $800-\mathrm{Hz}$ sine wave tone at $40 \mathrm{~dB}$ above threshold increased as its duration decreased below 250 msec. Os couid detect a $3-\mathrm{Hz}$ change with a tone duration of $250 \mathrm{msec}$, but required a $7-\mathrm{Hz}$ change if the tone was shortened to 20 msec.

Intensity can also be an important variable affecting pitch discrimination. Turnbull (1944) showed that a decrease in tone intensity from 60 to $20 \mathrm{~dB}$ increased the difference limen for pitch. Reducing tonal intensity had a larger effect when the comparison tone lasted $35 \mathrm{msec}$ than when it lasted 100 msec. Differences in intensity may also account for differences in the minimal duration for optimal frequency discrimination reported by Békésy and by Turnbull for similar tones. Comparing Békésy's

* This investigation was supported in part by U.S. Public Health Service Grant MH 19399-01 and a grant from the Wisconsin Alumni Research Foundation. I thank Barbara $K$ ahn for her assistance in carrying out the experiments. I would also like to thank the editor, Irwin Pollack, and the two reviewers for helpful comments on the manuscript.

tRequests for reprints should be sent to Dominic W. Massaro, Department of Psychology, University of Wisconsin, Madison, Wisconsin 53706. and Turnbull's results, it appears that a decrease from 60 to $40 \mathrm{~dB}$ in tone intensity doubles the minimal duration necessary for optimal frequency discrimination. increasing the duration of a repetitive wave pattern enhances the perception of the pitch quality of that pattern. Creel et al (1970) have shown that patients with an impaired blood supply to the brain stem have poorer tonal recognition than do normals. These patients require 200 to $400 \mathrm{msec}$ of a $1,000-\mathrm{Hz}$ tone to perceive it as a tone rather than a noise. In contrast, a normal listener needs a minimum of about $10 \mathrm{msec}$ of a tone burst for a tonal sensation (Stevens \& Davis, 1938). Patients with certain impairments, then, require more information than do normals to perceive tonal quality.

Recent studies have shown that perceptual processing time is also important for accurate pitch perception (Massaro, 1970c, 1971). Perceptual processing time refers to the presentation time of the signal which includes both the duration of the signal and the silent interval afterward (Massaro, 1970b). In Massaro's (1970c, 1971) studies, processing time was manipulated by varying the duration of the silent interval after a test tone presentation of 20 msec. Os identified the pitch of a high or low test tone followed by a masking tone after a variable silent masking tones were presented at $81 \mathrm{~dB}$. Os identified the high test tone as high and the low test tone as low. Although the Os heard the test tone on every trial, the masking tone interfered with pitch perception. Identification of the test tone improved with increases in the silent 250 msec. Increases in perceptual
These results indicate that intertone interval. The test and intertone interval up to about processing time also improves pitch identification performance.

The results indicate two processes responsible for accurate perception of pitch. First, the improvement in pitch discrimination with increases in tone duration and intensity can be attributed to an increase in the information in the stimulus (cf. Doughty \& Garner, 1947). The distribution of energy in a tone spreads across a range or bandwidth of frequencies centered at the tone frequency. Since the bandwidth of energy is inversely proportional to the duration of the tone, increasing tone duration increases the stimulus information available. Second, the improvement in pitch identification with increases in the retroactive silent interval is assumed to be due to an increase in perceptual processing time which is necessary for accurate perception (Massaro, 1970b, 1972). The present study aims to determine the relative contribution of stimulus information and processing time in an absolute pitch identification task. ${ }^{1}$

In Massaro's (1970c, 1971) studies, identification improved with increases in the silent interval up to 250 msec. The results indicate that optimal perceptual processing of a 20 -msec tone requires at least $1 / 4 \mathrm{sec}$. It is possible that tones longer than 20 msec do not require 250 msec for accurate pitch identification. Kahneman (1968), reviewing the visual masking literature, concluded that stimuli longer than 100 msec were not vulnerable to masking stimuli. Contrasting this, identification might be a continuous process that lasts longer than some arbitrary duration of the stimulus (Massaro, 1970b, 1972). Therefore, it is of interest whether a masking tone can terminate perceptual processing of tones lasting longer than the 20-msec tones used by Massaro (1970c, 1971). Some evidence for this is found in a study of short-term recognition memory for pitch (Massaro, 1970a). In a delayed comparison task, an interference tone presented immediately after a 200-msec test tone decreased its memory strength relative to delaying the interference tone. The parameter estimates of a simple storage-forgetting model of performance indicated that delaying the interference tone enhanced the storage or perception of the test tone. Since this result required a theoretical measure of the perceptual component in a memory task, a more direct study of a test tone's vulnerability to masking as a function of its duration is needed.

The present study also determines whether perceptual processing during the silent intertone interval is as efficient as processing a continuous 


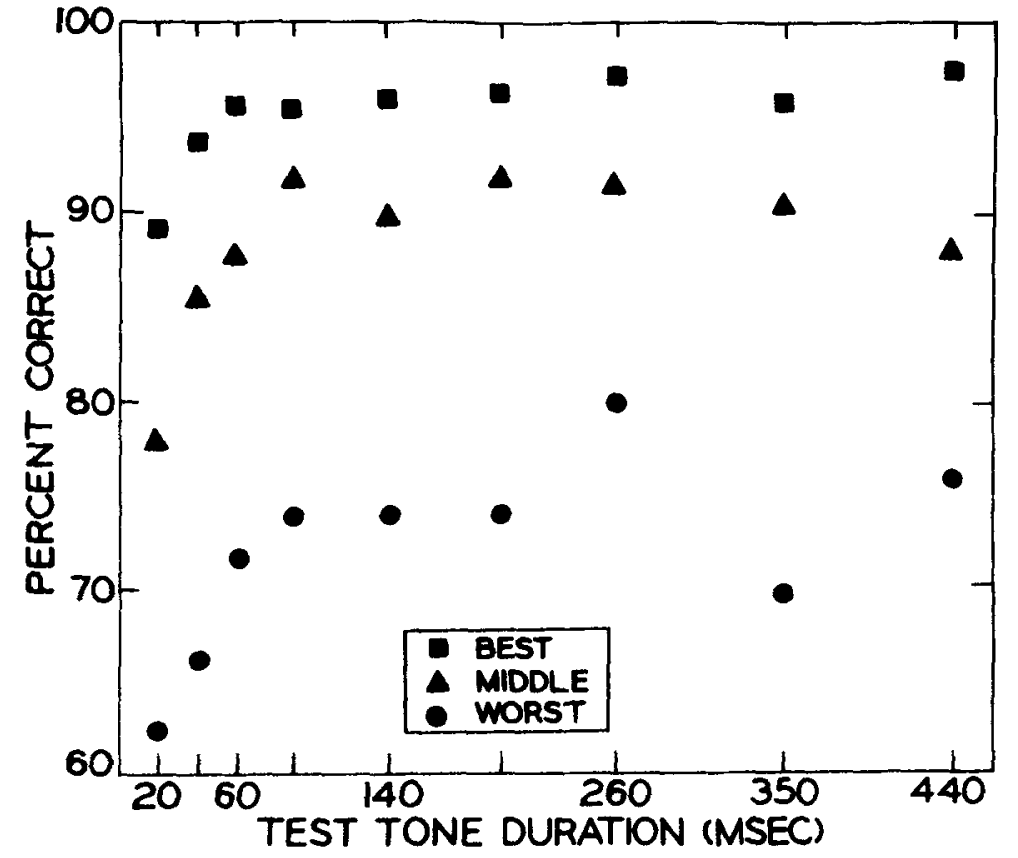

Fig. 1. Percent correct identification responses for the three groups on Day 1 as a function of the duration of the test tone.

tone. As noted above, increasing a tone's duration increases its pitch discriminability because an increase in duration increases the information available (up to some point) in the tone presentation. However, in addition to the gain in information, will perceptual processing of a continuous tone differ from perceptual processing during the silent interval after a short tone presentation? For example, Turnbull (1944) found that increases in duration of a $1,024 \cdot \mathrm{Hz}$ comparison tone beyond $100 \mathrm{msec}$ did not improve pitch identification. His results have at least two possible explanations. First, assuming that the tone was not completely processed within $100 \mathrm{msec}$, the results indicate that Os were able to process the information made available by the tone presentation during the silent interval after its presentation. Second, it may be that the tone was processed within $100 \mathrm{msec}$ and no further processing was required during the silent interval. The present study tests these two alternatives by first determining the amount of information gained with increasing duration of the tone. $A$ direct comparison can then be made between perceptual processing during the silent interval after the tone and perceptual processing during the continuous tone presentation.

The comparison between the efficiency of tone presentation time and perceptual processing time is analogous to a study of visual letter recognition by Haber and Nathanson (1969). These investigators measured the number of letters an $O$ could report in a display of sequentially presented letters. Duration of each letter and processing time (measured by the onset of one letter to the onset of the next letter) were covaried independently. The results indicated that processing time predicted the number of letters correctly reported, independent of the duration of letter presentation.

In the present study, the contributions of tone duration and processing time are compared to determine which predicts pitch identification best. In Experiment 1, pitch identification of a test tone presented for $20 \mathrm{msec}$ is compared to identification of the test tone presented at eight other longer durations, with perceptual processing time held constant. In Experiment 2, four durations of the test tone are covaried independently of eight silent processing intervals.

\section{EXPERIMENT 1 Method}

Forty-five undergraduates fulfilling a course requirement at the University of Wisconsin were employed in the present study. The absolute judgment task required the $O$ to identify a sawtooth wave of $800 \mathrm{~Hz}$ as "sharp" and a sine wave of $800 \mathrm{~Hz}$ as "dull." In the masking conditions, the test tone was followed by a square wave of $800 \mathrm{~Hz}$ after a variable silent interval. These test and masking tones differ only with respect to the higher harmonics of $800 \mathrm{~Hz}$. A pure tone consisting of sawtooth waves sounds sharp relative to the dull sound of a pure tone consisting of sine waves. The square wave, which sounds like buzz, lasted 240 msec and is referred to as the masking tone. The onsets and offsets of the tones were essentially instantaneous.

If the silent intertone interval is to represent processing time accurately, the test and masking tones must be roughly equal in loudness. All tones in the present study were presented at $50 \mathrm{mV}$ peak-to-peak intensity (about $76 \mathrm{~dB}$ SPL). To determine whether these tones were equal in loudness, latencies of simple detection responses were recorded from two practiced $\mathrm{Os}$ in a reaction time experiment. McGill (1961) has shown that simple reaction times provide a good index of stimulus loudness. Average reaction times to the saw, sine, and square waves were 151,161 , and 154 msec, respectively. These latencies indicate that the tones in the present study were roughly equal in loudness, and therefore the intertone interval provides a reliable measure of perceptual processing time.

On the first day of the experiment, Os identified the pitch quality of the test tone. The duration of the test tone was $20,40,60,90,140,200$, 260,350 , or $440 \mathrm{msec}$. The test tone lasting $\mathbf{2 0}$ msec was presented as often as the other durations combined. All nine experimental conditions were completely random within a given session. Two sessions of $\mathbf{3 0 0}$ trials each were given, and Os did not respond to the first five trials of each session. Therefore, the 20-msec test tone was presented about 295 times and the other eight durations about 37 times each.

On the second day, the masking tone was introduced. In the silent processing condition, the test tone was presented for $20 \mathrm{msec}$, followed by a silent interval of $30,50,80,130,190$, 250,340 , or $430 \mathrm{msec}$, followed by the masking tone. In the continuous processing condition, the test tone was presented for $40,60,90,140,200$, 260,350 , or $440 \mathrm{msec}$, followed by a silent interval of $10 \mathrm{msec}$, followed by the masking tone. All 32 experimental conditions ( 2 test tones by 2 processing conditions by 8 processing intervals) were completely random in a given session and were programmed to occur equally often. Therefore, on every trial on Day 2, Os heard a test tone of variable duration, followed by a variable silent interval, followed by the masking tone. They identified the test tone as "sharp" or "dull" and were then informed of the correct answer for that trial. As on Day 1, two sessions of 300 trials each were given 
and $O$ s did not respond to the first five trials of each session. Therefore, each $O$ contributed about 37 observations to each processing condition by processing interval condition.

All experimental events were controlled by a PDP-8L computer. Four Os could be tested simultaneously in separate sound-attenuated rooms. The pure tones were produced by a digitally controlled Wavetek Model 155 oscillator. The tones were presented binaurally over matched Grason-Stadler Model TDH-49 headphones mounted in 001 headsets. Each O recorded his "sharp" or "dull" decision by pressing one of two pushbuttons labeled "sharp" and "dull," respectively. Following a $1.5-\mathrm{sec}$ response period, feedback was presented by illuminating a small light for $500 \mathrm{msec}$ above the correct response button. The intertrial interval was 2 sec.

The performance of Os differs widely in this task. Os were divided into three groups of 15 Os each according to their overall discrimination performance on Day 1. The three groups are designated worst, middle, and best, respectively. This should help reduce the problems with averaging results of $\mathrm{Os}$ with major differences in overall performance.

\section{Results}

The identification of the test tone on the first day improved with increases in the duration of the test tone. Fig. 1 shows percent correct identifications for each group as a function of the duration of the test tone. For all groups, identification performance improved with increases in test tone duration up to about $\mathbf{4 0}$ or $60 \mathrm{msec}$. Beyond 40 or $60 \mathrm{msec}$, increasing the duration of the test tone had no consistent effect on identification performance.

Figure 2 presents the observed percent correct identifications on Day 2 for each group as a function of the silent or continuous processing condition and the processing time available. Averaging across groups, correct pitch identification increased $17 \%$ in both the silent and continuous tone conditions, with increases in the processing time available. Figure 2 shows that overall performance averaged across groups was $3 \%$ better in the continuous tone condition than in the silent condition. These two results indicate that increasing processing time was about six times more effective in improving identification performance than increasing the duration of the test tone.

An analysis of variance performed on the percent correct identification with groups, Os, processing condition,

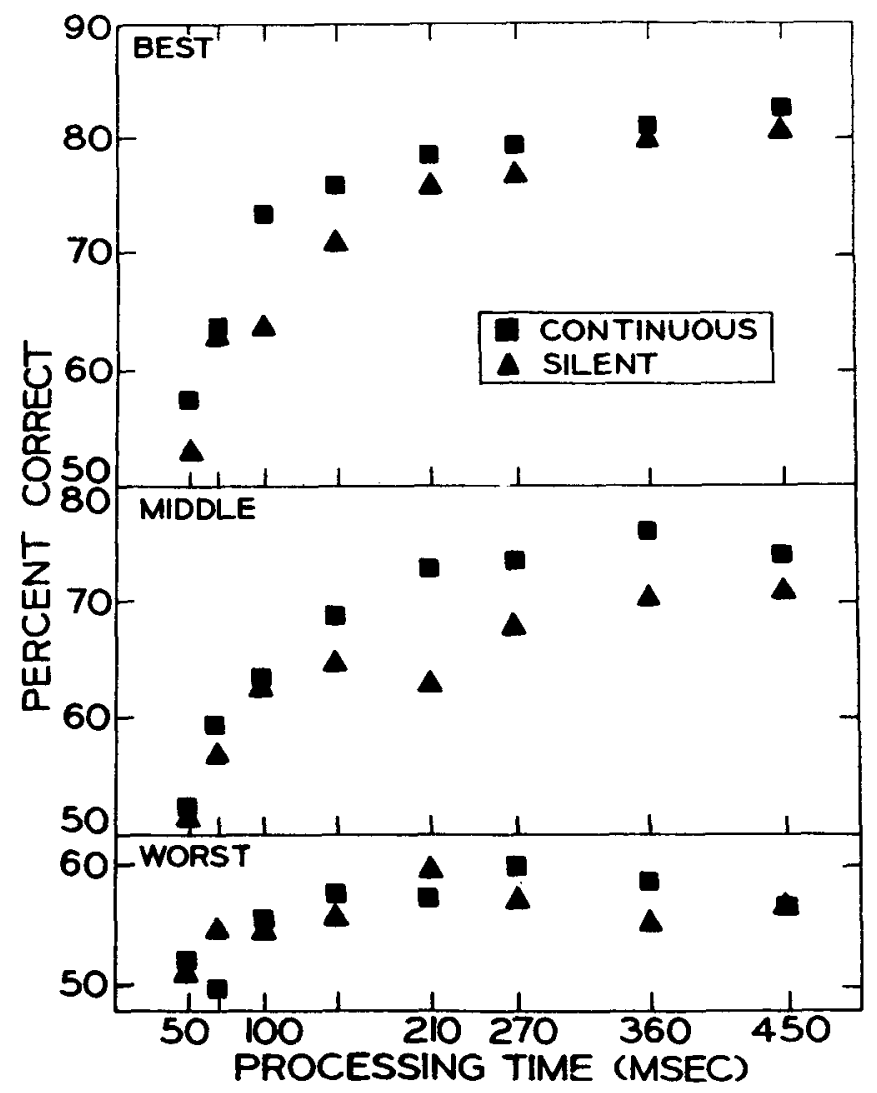

Fig. 2. Percent correct identification responses for the three groups on Day 2 as a function of the processing condition (continuous or silent) and the processing time available.

ad processing time supports these conclusions. Identification performance was better in the continuous tone condition than in the silent interval condition $[F(1,42)=$ $6.89, \mathrm{p}<.025]$. Performance also showed a large improvement with increases in the processing time available $[F(7,294)=45.44$, $\mathrm{p}<.001]$. These two independent variables had additive effects on identification performance; their interaction was not significant $[F(7,294)<1]$.

Figure 2 also provides a graphic analysis of how processing condition and processing time affected each of the three groups. The continuous vs silent processing condition had roughly the same effect in each group. In contrast, the improvement in performance with increases in processing time increased with increases in overall group performance $[\mathrm{F}(14,294)=4.99, \quad \mathrm{p}<.001]$. Increasing processing time from 50 to $450 \mathrm{msec}$ improved performance by $6 \%, 21 \%$, and $26 \%$ for the worst, middle, and best groups, respectively. This result indicates that the processing time variable also provides a good index of individual differences.

The results indicate that processing time is more important for accurate tone identification than stimulus duration. Performance is very near chance if the $O$ has only $50 \mathrm{msec}$ of processing time available. However, a 20-msec tone can be identified about $70 \%$ of the time if the $O$ has 270 msec to process the information in the test tone presentation. Furthermore, the improvement in test tone identification with increases in processing time occurs at roughly the same rate during the continuous and silent processing conditions.

\section{EXPERIMENT 2 Method}

Sixteen undergraduates fulfilling a course requirement participated in this experiment for 4 days with two sessions of 300 trials each per day. Os were practiced with the test tones without the masking tone on Day 1. On Days 2, 3, and 4, four durations of the test tone were covaried with eight silent intertone intervals. The test tone lasted 20, 40, 60, or 80 msec. The silent intertone interval lasted 20,40 , $70,120,180,240,330$, or 420 msec. The masking tone always lasted 80 msec. All 64 experimental conditions ( 2 test tones by 4 test tone durations by 8 intertone intervals) 


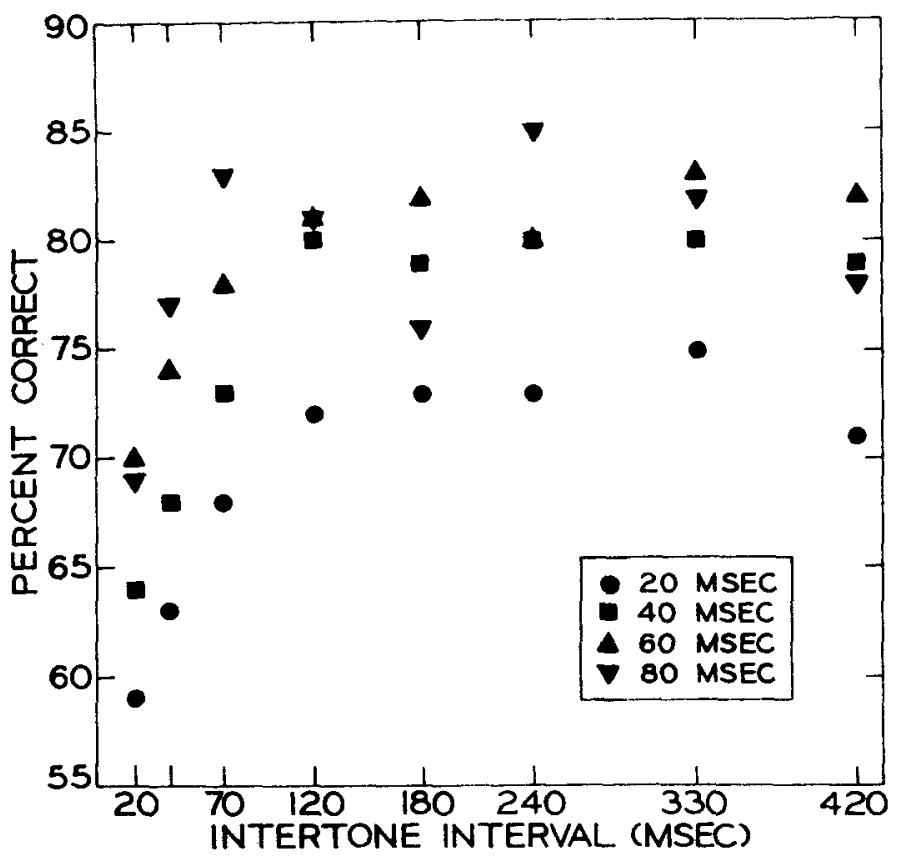

Fig. 3. Percent correct identification responses as a function of test tone duration and the silent processing time available.

were completely random in a given session and occurred about equally often. All other procedural variables were the same as in Experiment 1. Only the results of the last 2 days of the study were used in the data analys is. Therefore, each $O$ contributed about 37 observations at each test tone duration by intertone interval condition.

Figure 3 presents the average percent correct identifications for the 16 Os on Days 3 and 4 as a function of the test tone duration and the silent intertone processing interval. The graph shows significant contributions of both test tone duration and silent processing time. Identification performance improved with increases in the test tone duration $[F(3,45)=$ 9.75, p <.001]. Averaged over the silent interval, correct identifications occurred $64 \%, 75 \%, 79 \%$, and $79 \%$ of the time for the 20-, 40-, 60-, and $80-\mathrm{msec}$ test tones, respectively. Identification also showed an overall $12 \%$ improvement with increases in silent perceptual processing time $[F(7,105)=20.17, p<.001]$. Figure 3 shows that test tone duration and silent processing time had additive effects on identification performance $[F(21,315)=1.47, \mathrm{p}>.10]$.

\section{DISCUSSION}

The present results provide a test of a perceptual model of stimulus identification (Massaro, 1971b, 1972). The two main assumptions of the theory describe the perceptual process in terms of the information in the and the processing time available. sensory input and the time the information is available for perceptual processing. The first assumption of the theory is that an auditory input produces a preperceptual auditory image that contains the information in the auditory stimulus. The preperceptual auditory image can be thought of as a temporal unit of information. Therefore, the image persists beyond the stimulus presentation and preserves its sequential information. The second assumption is that the recognition process entails a readout of the information in the preperceptual auditory image. This readout increases the strength of the item and is referred to as the temporal course of perceptual processing.

Massaro (1970b, 1972) has presented evidence that supports the two main assumptions of the theory. Perceptual processing outlasts the sensory input so that the preperceptual auditory image is necessary for accurate identification. The preperceptual image is similar to the auditory image present during the stimulus presentation. In the present study, the masking tone appears to terminate perceptual processing of the test tone because it interferes with the auditory

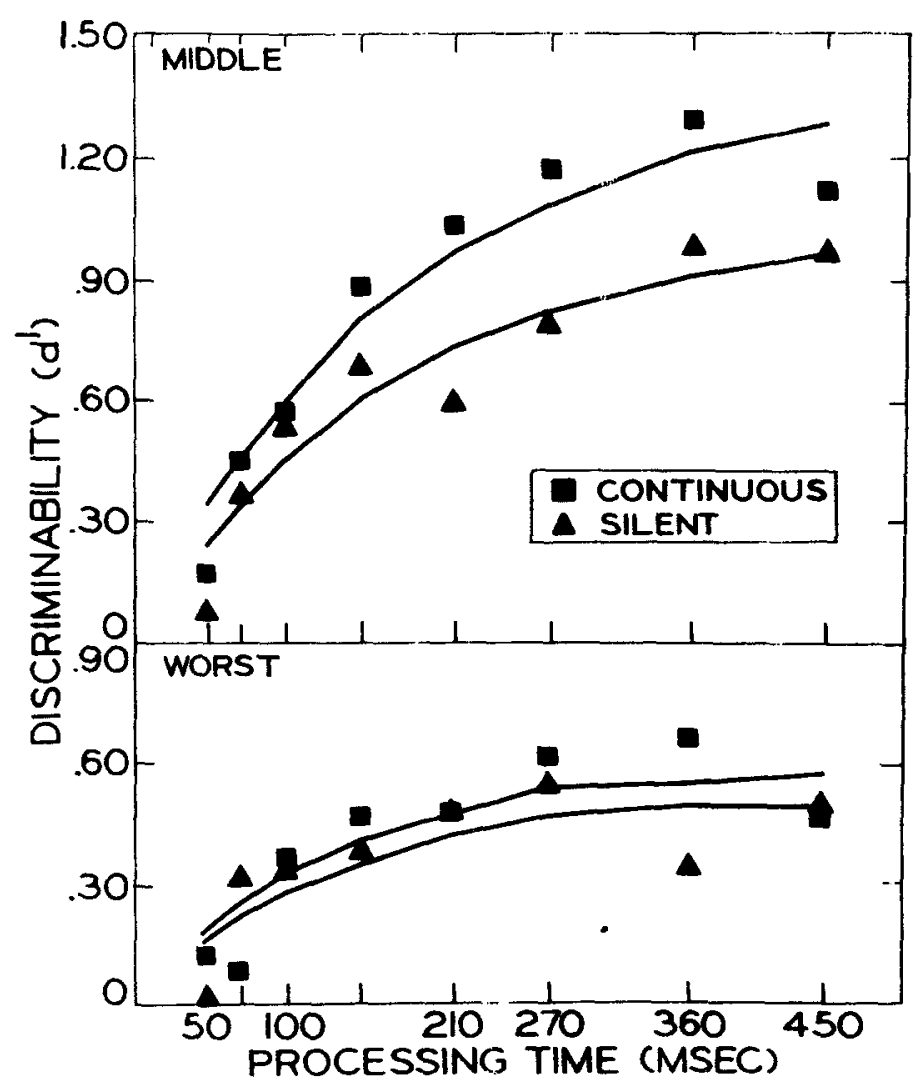

Fig. 4. Predicted and observed discriminability (d') values for the worst and middle groups as a function of the processing condition (continuous or silent) 
image (Massaro, 1971) It is powible that the masking tone does not interfere with the anditiony imase, but simply preverst perceptuol procesions. In this case, a short tone wonld not be an effective masking tone, sines 0 s condil continue to process the anditiony imace of the test tone after the dhont masking tone terminated. Howerer, the result ind incte that decreasing the duration of the madking tone from 500 to 20 meec does not decrease masking or interference (Marearo, $\left(1971^{2}\right)$. Therefore, the onset of the masking tone seems to interfere with perceptual procesaing of the test tone by decreasing the signal-to-noise ratio of the auditory image.

Kain and Massoso ${ }^{3}$ have shown that the interference effect of the masking tone is not due to a simple switeh in the $O$ 's attention. It is possible that the masking tone distracts the O's attention and therefore prevents perceptual processing of the auditory image. In this case, the processing of a nonauditory stimulus should also interfere with pitch identification. Light and tone masking stimuli were employed in the pitch identification task. Os were also required to identify the duration (long or short) of the madring stimanlus to direct their attention to the light masking stimalus. The resulte indicated that the moning light did not interfere with piteh identification. These results smpport the bypothesis that the moning tone interferes with pitch identification because it decreases the information arailable in the auditory imase.

In the formal theory, the perceptual strength of an item follows an exponential growth function of time:

$$
s(t)=\alpha\left(1-e^{-\theta t}\right)
$$

where $s(t)$ is the perceptual strength of the item after a presentation time of t sec. Presertation time includes both the duration of the item and the retroective silent interval. Equation 1 indicates that the strength of a single item approaches a finite asymptote $\alpha$ at rate $\theta$. This implies that percent correct identifications increase with increases in $s(t)$.

Each item is assumed to have a certain amount of stimulus information. An item with more information would be expected to have a larger value of $\alpha$. A noisy or unclear item would have less stimulus

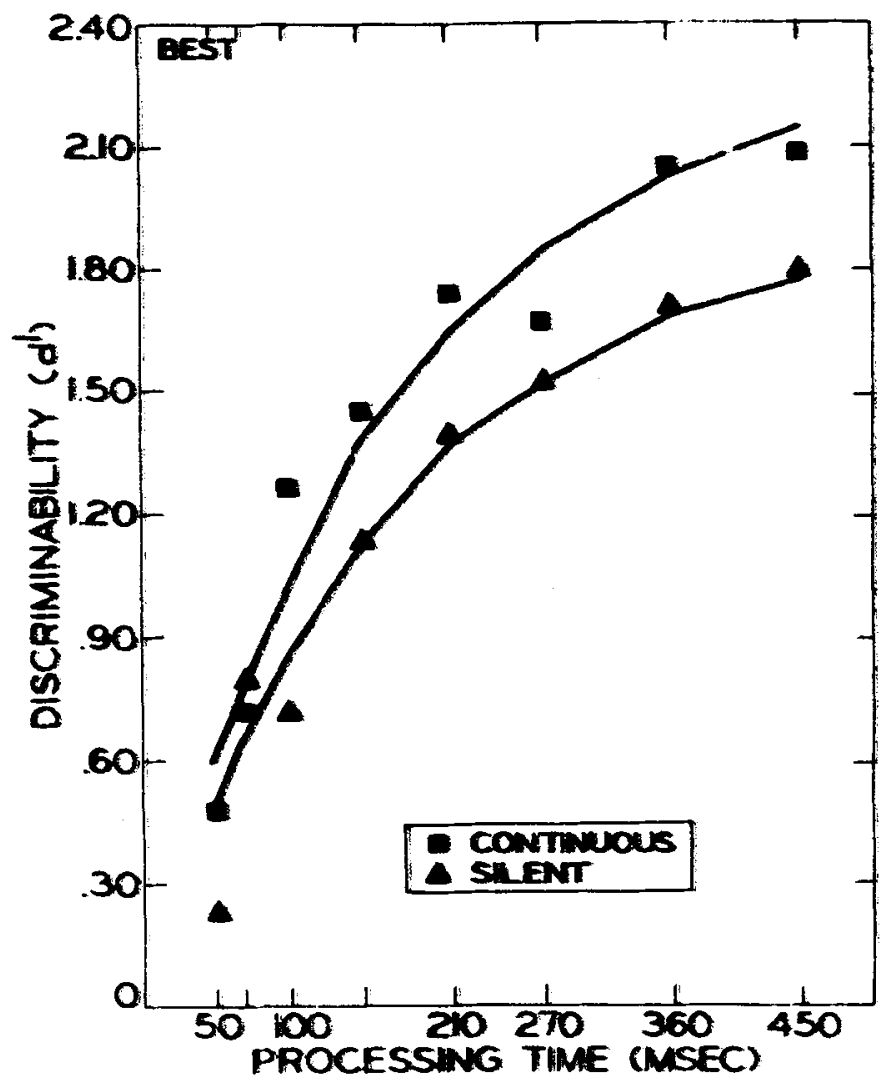

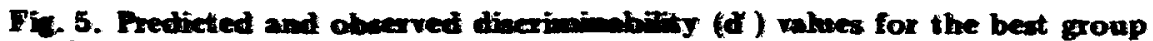
as a function of the procending condition (combinuous or silent) and the procesting time availuble.
Table 1

Parameter Eatimates for Equation 1 of the Pereeptual Proeerine Model Desedibial the Tenaporal Courne of Teat Tome

Idenofiention in Expeximent 1

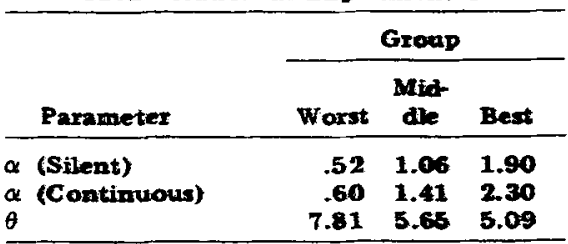

information and, therefore, a mallex value of $\alpha$. The rate at which the stimulus information is processed is reflected in the value of 0 . Thus, the values of a and $\theta$ provide indexes of stimulus information and rate of perceptual processing, respectively. In the framewort of the perceptual procesing model, increasing the duration of the test stimulus should increase its stimulus information up to some point but should not affect the rate of procesing this information. Accordingty, in the present study, increases in the duration of the teat tone should affect $\alpha$, the index of stimulus information, but not $\theta$, the rate of perceptual procensing.

According to the model, identification is determined by the perceptual strength of the item. In the prevent tak, it it acoumed that the 0 choose a criterion vilue alone cherp-dull dimencion and reponds "sharp" if and coly if the item's strength exceeds the criterion. Therefore, observed $(t)$ volues correspond to the $d$ values of rignal detection theory (Mararo, 1970b) The pereeptual procering model wo applied to the dinta from ench of the three groups in Bxpeximent 1. otened of vlues were computed by fust pooline the rexpowe fiequencies orer the 0 - in exch roop. Then rexpone probabilitios were compoted at ean experimental condition. The pubabitity of recponding "dharp" given the awtooth wave, P(charp a sed wreh rabiturity dexignated a a hit, and the probubitity of repponding "Lap" piven a sive wave, P(shorp ! sine wovel was deciponated a falce alom. The oberved of volwes were determined by uing the twles given by Eoriot (1964) The predietied of values crese obtinined by edtinating the perrancter vlues of Eq. 1 wing reiterative search routine that minimived the squane deviation. between the predieted and observad of valued.

In Bxperiment 1, the procesing interval we either silent or continuoes with the test tone. Increasing the duration of the test tone shonld imereane ite stimulu information up to some point. The main effect of the silent $r$ continuote procering 


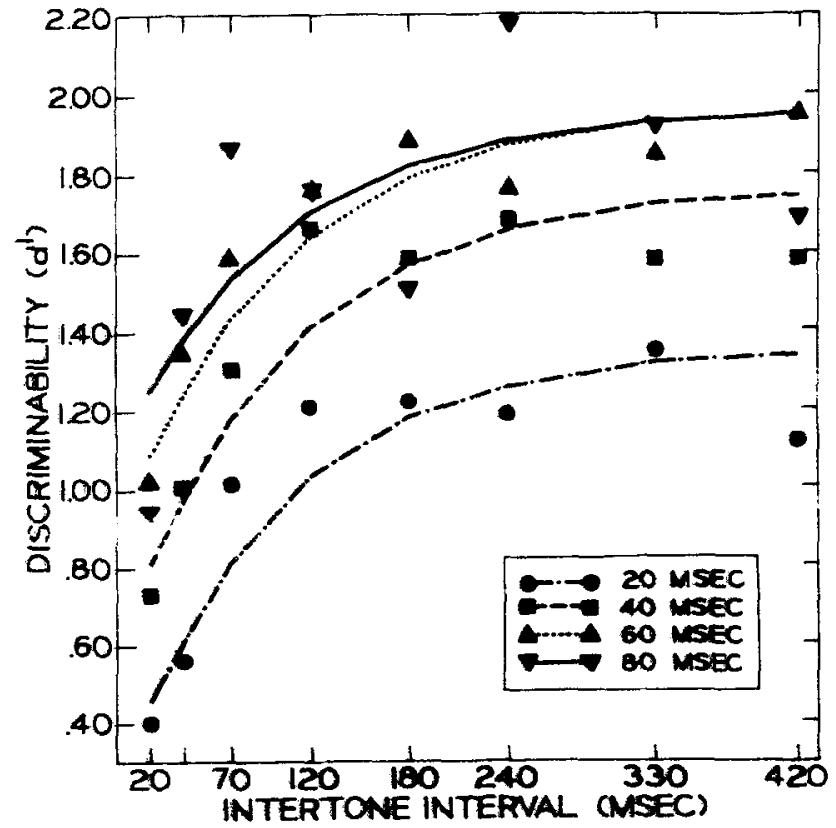

Prs. 6. Predicted and cherved discrimimbility (d') values as a fanction of teat tone duration and the sient proceming time avnilable.

condition indicated that the tones in the continuous procesing condition bad mose stimules information than the 20-moce tone. It is reanonsble to somene that the amonat of ainulus information in the 20 -wase teat tone

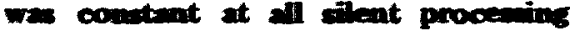
interval. Therefore, the nosiguifent internetion of procening ocodition with procening tive indiented that ctimulas information wo tho relatively constant within the continuous tone condition. Acoonding, a diffecent value of $a$, the

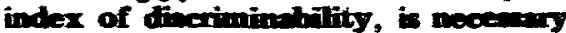
for the silent and continmone proveseing conditions Purthermone,

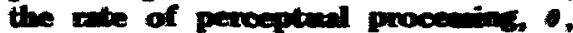
thould be equal in the eilout and oontimons condition. Given ethe procening intervels at both the contionow and thent procemine condition 16 dith point are predicted uins three permeter etingter.

The observed and predieted divorimingitity (d) values for the these swoup ane presuted in Fr. 4 and 5 . The peroneter etirate ane pecented in Trible 1 . The extimated pilue of $\alpha$ is brer for the continuowe coudition than for the ilent condition for all exoupe. This nesult indientes that with procening time held condtant, the continucas tore provides. slightly more information for identifiction than a 20-moe teat tooe. The rood description of the reavilts supports the anmption that the onict of the monking tore terminaties peroeptand procersing of the text tone. The revult are abo described accurately, with the restriction that the rate of peroeptar procensing is the ene for both the gilent and oontinuous tome conditions. This indicates that the efficiency of procesing information in an anditory imare of a tone does sot difier from processing information in the contimuous tone itwelf. The anditory afterimo, then, does not som to differ qualithtively from the anditory image during the test tome presentation.

In Bxperiment 2 , stimalas information was inerened by increasing the duration of the best tone. Procening tine wres increaned by incxe in both tert toue daretion and silent intertone interval Ite

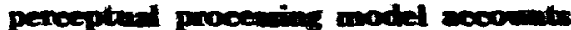
for increanes in the informetion in the

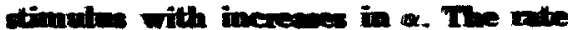

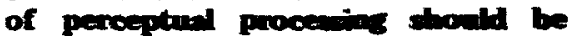
constant ander alloriontion conditione. Furthermane siose owerl perfocm noe did not difier with thet to $=$ of 60 and 80 moce, ond owe vilue of $\alpha$ ars extionated for there tho coudition Therefore, the whes of $\alpha$ and one value of $i$ mere for the 32 experiventel ocmilition. The observed and predicted of walnos wene computed as in Brpecineat 1.

Figure 6 prencuts the observed and

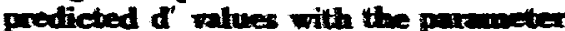
extimates presented in Tribles. The extimated values of $\alpha$ increwese with tout tone dumtion. The model tiven a remoutble description of the realth, with the refriction that the rute of

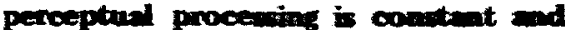
independent of the duation of the test stimulus. Therefore, the results of Experiment 2 also support the assumed distinctions between stimulus information and perceptual processing time.

The present results are relevant to studies of perceived duration of short auditory stimuli. If the auditory afterimage is continuous with the auditory image present during the tone presentation, Os may mistake the afterimage for the sctul tone presentation. Supporting this, the revults of Efron (1971a, b, e) and Goldburt (1961) indicate that $O$. overestimate the duration of short tones. In Efron's studies, $O$ s estimante the duration of tones hocter than 130 misec to be sbout 130 misec. This reoult indieates that the anditory afteriture of a thort toos dow not sean to be decontinuoes with the

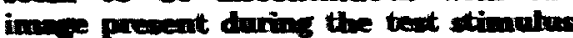
perentertion. Goldout (1961) bas shome that a second tore preseated innuediately afler a brief bone borteas its percoived daration. In reveruent with the present reculter, Golpdbart's reinits indiente that a roond tone can erme the anditory innose from an ealier towe prescatation.

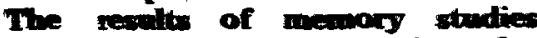
vaning the rate of perentation of a lit of watbel iteons tho indicate thet presentation tine en iniluenoe the perowithel thenth of the ithens (N) 1970, Norman, 1966;

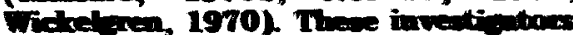
have Inom thet deciensing the

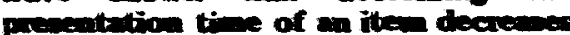
the peropption ( 0 mensured by the there component of a werogry anodal) of the ithen. What is atriking

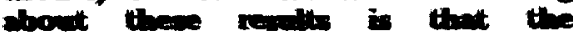
Preventhition times mere betwees 100

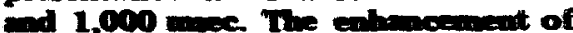

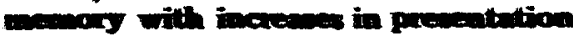

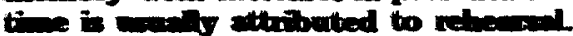

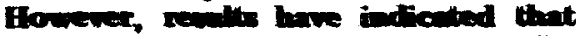

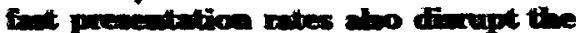
perception of the tent ibuas

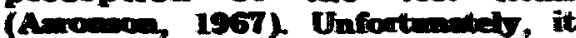
vill be inicult to inolute the contributions of peroeption and

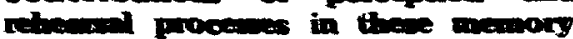
the

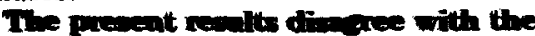

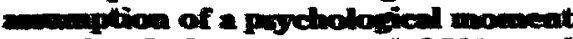
porthertod of strond (1955) and

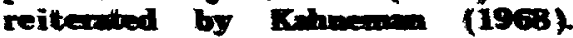

Indere 2

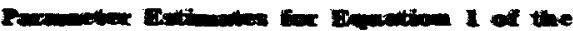

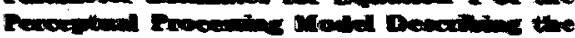

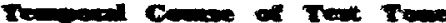

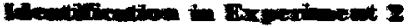

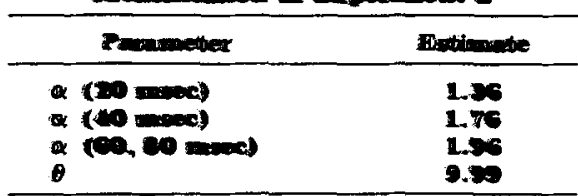


According to the theory of psychological moment, the perceptual experience occurs within a psychological moment of time. After the moment, a second input should not disrupt the perceptual experience of the first input. For example, Kahneman concludes that a stimulus presented for $100 \mathrm{msec}$ or more will not be masked by a stimulus of equal intensity. In contrast, the present results indicate that perception of an event is not determined by some arbitrary stimulus duration but rather is a continuous analysis of the information available to the 0 .

In most visual recognition masking studies, masking has not been found to exceed $100 \mathrm{msec}$. However, in these studies (Erikson, Becker, \& Hoffman, 1970; Weisstein \& Haber, 1965), two letters are usually employed as the stimulus alternatives. Given only two overlearned stimulus alternatives, it seems reasonable that recognition can take place within 100 msec. Decreasing the distinctiveness of the alternatives or increasing the number of alternatives, however, should increase the time necessary for perception. In this case, backward masking should occur at intervals exceeding $100 \mathrm{msec}$.

The absolute judgment task has certain similarities with delayed comparison studies of pitch memory (Massaro, 1970a, b; Wickelgren, 1966, 1969). The important difference is that the operation of the masking tone in the absolute judgment task differs from the operation of the interference tone in the delayed comparison task. $A$ second tone can affect both perception and memory of an earlier tone. A second tone interferes with perceptual processing of a first tone and also interferes with the memory trace of the synthesized percept over time. Only the first operation is important in the identification task, whereas both operations are important in the delayed comparison task. Since the onset of the masking tone interferes with perceptual processing of the test tone, the identification or readout of the test tone must occur before presentation of the masking tone. Accordingly, the duration of the masking tone has no effect on absolute identification performance (Massaro, $1971^{2}$ ).

In the delayed comparison task, the
$O$ acquires a memory trace for later test. As in the absolute identification task, the onset of the interference tone ends perceptual processing of the test tone. However, the $\mathrm{O}$ must remember the test tone (no matter how weak the trace) for later test. The interference tone now functions to decrease the memory strength of the test tone. Accordingly, increasing the duration of the interference tone in the delayed comparison task decreases recognition memory for the test tone (Massaro, $1970 \mathrm{a}, \mathrm{b}$; Wickelgren, 1966, 1969).

\section{REFERENCES}

AARONSON, D. Temporal factors in pereeption and short-term memory. Psychological Bulletin, 1967, 67. 130-144.

ANDERSON, D. A. The duration of tones, the time interval, the direction of sound, darkness and quiet, and the order of stimuli in pitch discrimination. Psychological Monographs, 1914, 16, $150-156$.

BÉKÉSY, G. von. Experiments in hearing. New York: McGraw-Hill, 1960.

CREEL, W., BOOMSLITER, P. C., \& POWERS, S. R. Sensations of tones as perceptual forms. Psychological Review, 1970, 77, 534-545.

DOUGHTY, J. M., \& GARNER, W. R. Pitch characteristics of short tones: I. Two kinds of pitch threshold. Journal of Experimental Psychology, 1947, 37 Experime

EFRON, R. Effect of stimulus duration on perceptual onset and offset latencies. Perception \& Psychophysics, 1970a, 8 , 231-234.

EFRON. $R$. The minimum duration of perception. Neuropsy chologia, $1970 \mathrm{~b}, 8$, $57-63$.

EFRON, R. The relationship between the duration of a stimulus and the duration of a perception. Neuropsychologia, $1970 \mathrm{c}, 8,37-55$.

ELLIOT, P. B. Tables of d'. In J. A. Swets (Ed.), Signal detection and recognition by human observers. New York: Wiley, 1964 .

ERIKSON, C. W., BECKER, B. B., \& HOFFMAN, J. E. Safari to masking land: A hunt for the elusive $U$. Perception \& Psychophysics, 1970, 8, 245-250.

GOL'DBURT, $S$. N. Investigation of the stability of auditory processes in micro-intervals of time (new findings on back masking). Biofizika, 1961, 6 , 717-724. English translation: Biophysics, $1969,6,809-817$.

HABER, R. N., \& NATHANSON, L. S. Processing of sequentially presented letters. Perception \& Psychophysics, $1969,5,359-361$.

KAHNEMAN, D. Method, findings and theory in the studies of visual masking. Psychological Bulletin, 1968, 70 404-425.

MASSARO, D. $w$. Consolidation and interference in the perceptual memory system. Perception \& Psychophysics, $1970 a, 7,153-156$.
MAssaro, D. W. Perceptual processes and forgetting in memory tasks. Psychological Review, 1970b, 77, 557-567.

MASSARO, D. W. Preperceptual auditory images. Journal of Experimental Psychology, 1970c, 85, 411-417.

MASSARO, D. W. Effect of masking tone duration on preperceptual auditory images. Journal of Experimental Psychology, 1971, 87, 146-148.

MASSARO, D. W. Preperceptual images, processing time, and perceptual units in auditory perception. Psychological Review, 1972, 79, 124-145.

McGILL, W. J. Loudness and reaction time. Acta Psy chologica, 1961, 19, 193-199.

NORMAN, D. A. Acquisition and retention in short-term memory. Jourmal of Experimental Psychology, 1966, 72. 369-381.

STEVENS, S. S., \& DAVIS, H. Hearing. New York: Wiley, 1938 .

STROUD, J. M. The fine structure of psychological time. In H. Quastler (Ed.), Information theory in psychology. Glencoe, Ill: Free Press, 1955.

TURNBULL, $W$. W. Pitch discrimination as a function of tonal duration. Joumal of Expeximental Psychology, 1944, 34, 302-316.

WEISSTEIN, N. \& HABER, R. N. A $U$-shaped backward masking function in vision. Psychonomic Science, 1965, 2 . 75-76.

WICKELGREN, W, A. Consolidation and retroactive interference in short-term recognition memory for pitch. Journal of Experimental Psychology, 1966, 72, 250-259.

WICKELGREN, W. A. Associative strength theory of recognition memory for pitch. Joumal of Mathematical Psychology, $1969,6,13-61$.

WICKELGREN, W. A. Time, interference, and rate of presentation in short-term recognition memory for items. Journal of Mathematical Psychology, 1970, 7 . 219-235.

\section{NOTES}

1. It should be noted that an absolute judgment task is the appropriate paradigm for determining a psychometric function of pitch discrimination as a function of tone duration. A successive comparison task would confound processing time with stimulus duration if the standard and comparison stimuli were presented for the same duration. To hold processing time constant, one could fix the duration of the standard tone so that processing time is optimal and then, systematically vary the duration of the comparison tone. This was the procedure employed by Turnbull (1944) and is not appropriate, since the short comparison tone will also sound different from the longer standard tone because of differences in duration. In the absolute judgment task, the duration of the two test tones can be varied without confounding processing time or memory.

2. Massaro, D. W. Backward recognition masking as a function of masking tone duration, in preparation.

3. Kahn, B., \& Massaro, D. W. Effects of attention on perceptual processing, in preparation.

(Received for publication Manch 4, 1972.) 